\title{
Ssciendo
}

Ethics \& Bioethics (in Central Europe), 2020, 10 (1-2), 48-58

DOI:10.2478/ebce-2020-0008

\section{Inappropriate hemodialysis treatment and palliative care}

\author{
Rudolf Novotný, ${ }^{1}$ Zuzana Novotná ${ }^{2}$ \& Štefánia Andraščíková ${ }^{3}$
}

\begin{abstract}
The paper discusses inappropriate (futile) treatment by analyzing the casuistics of palliative patients in the terminal stage of illness who are hospitalized at the Department of Internal Medicine and Geriatrics of the Faculty hospital with policlinic (FNsP). Our research applies the principles of palliative care in the context of bioethics. The existing clinical conditions of healthcare in Slovakia are characteristic of making a taboo of the issues of inappropriate treatment of palliative patients. Inductive-deductive and normative clinical bioethics methods of palliative care and ethical strategy are applied for defining issues found in inappropriate hemodialysis treatment. An algorithm of hemodialysis treatment requires the definition of those lege artis criteria which, in the context of a patient's autonomy and his/her decision, precondition the avoidance of the situation in which hemodialysis treatment is inappropriate (futile). Futile treatment in a terminal condition is ethically inappropriate medical treatment that extends the suffering of patients and their relatives. Its definition is determined by the relevant legislation and the methods of bioethics. An active palliative strategy is aimed at managing the process of incurable diseases in the patient's bio-psycho-socio-spiritual continuity in the process of special bioethics. The global bioethical objective of general bioethics for palliative care is based on the paradigm of social harmony and solidarity in the context of an authentic modus of the patient's existence as a constitutive principle for the phenomenon of the patient's being to finite being (death).
\end{abstract}

Keywords: hemodialysis treatment, futile treatment, bioethics, individualized prognostic strategy, palliative care

\section{Introduction}

The prevalence of chronic kidney diseases has been growing. Half of all dialyzed patients in Australia are older than 65 years, and $26 \%$ of patients are older than 75 years (Grace, Hurst \& McDonald, 2012). The fastest growing group of dialyzed patients in Great Britain are above 65 years (U. S. Renal Data System, 2014); in the Czech Republic, patients of the age above 60 years represent $70 \%$ of all dialyzed patients (Rychlík \& Lopot, 2017). The initiation of dialysis treatment of senior citizens is frequently connected with worsened functional condition and quality of life. An important role is played by comorbidities and frailty syndrome in the elderly. Age is not the only relevant factor. Dialyzed patients above 75 years of age are a fairly heterogenous group in which the survival period depends on the higher number of comorbidities, primarily IHD (ischemic heart disease) and unplanned dialysis initiation (Murtagh et al., 2007). The main symptoms are chronic pain, fatigue, cognitive deficiency and depression. These symptoms are present in as many as half of the patients (Hedayati et al., 2009). The data from abroad, covering the period from 1995 to 2010, indicate an increased mortality from $25.6 \%$ to $42.4 \%$ in patients above 65 years of age after the completion of dialysis as a result of the patients' end-of-life decision. (U.S. Renal Data System, 2011). The standard treatment of frail and high-risk patients who suffer from CKD (chronic kidney disease) affects their life values and can result in inappropriate treatment. Palliative/supportive care personalizes the treatment and correlates with the patient's values and life objectives. Integration of supportive care in standard CKF patient treatment is an indispensable condition forshowing respect for the human dignity and rights of patients. Abstracted 'classical' ethical principles do not favour the solution of specific fates of individual patients, especially in critical situations and at the end of one's life. In these cases situational ethics is applied. This kind of

\footnotetext{
${ }^{1}$ Faculty hospital of J.A. Reiman in Prešov; email: novotny.r@fnsppresov.sk

${ }^{2}$ University of Prešov, Faculty of Health Care

${ }^{3}$ University of Prešov, Faculty of Health Care
} 
situation requires the methods of applied ethics - the bioethics in order to implement desired ethical procedures because the classical ethical postulates are too strict in these situations.

\section{Objectives}

This paper discusses casuistics of three patients undergoing chronic dialysis treatment in order to manifest the necessity to define the critical condition and the terminal condition in a patient, and the possibility of intensive palliative treatment of dialyzed patients. Furthermore, the paper discusses issues regarding inappropriate hemodialysis treatment of terminal condition patients.

\section{Casuistics 1 \\ 81-year-old patient, hospitalized for 34 days in 2018}

\section{Pre-disease period}

The basic diagnosis identified chronic stage 5 K/DOQI (Kidney Disease Outcomes Quality Initiative - clinical guidelines) kidney failure, i.e., the terminal stage. The patient was included in a chronic hemodialysis program in 1999, HD was administered three times a week. The other chronic diagnoses included: chronic heart failure, function group NYHA IV (New York Heart Association) - terminal stage aggravated by repeated pulmonary edema. Chronic lung and bronchial obstruction disease accompanied with high pulmonary artery pressure. Organic delusional disorder (similar to schizophrenia).

Clinical frailty index (evaluated by testing daily activities, mental endurance, physical performance and nutrition): patient in the terminal stage, i.e., in the terminal frailty stage.

\section{Hospitalization}

The patient was hospitalized due to dyspnoea and fever. Hemodialysis treatment continued during the hospitalization, and was applied three times a week. The condition was diagnozed as sepsis. A targeted seven-day ATB treatment and complete supportive treatment resulted in a temporary improvement in clinical and laboratory results. The patient suffered from progressive signs of heart weakness. The following days brought progressive inflammation, the clinical picture showed strong pain, and the patient suffered from acute psychiatric syndrome with disorientation.

- $15^{\text {th }}$ day of hospitalization: consultations with an HD specialist (nephrologist) who decided to withdraw dialysis and evaluated the patient's condition as a pre-terminal condition due to instable blood circulation and low blood pressure. Since blood pressure increased the next day, the HD specialist recommended to resume hemodialysis and apply it three times a week.

- $27^{\text {th }}$ day of hospitalization: the condition worsened due to a blood clot in the right cardiac atrium, and poor performance of the left cardiac atrium with signs of heart failure (heavy dyspnoea and body edema).

- $34^{\text {th }}$ day of hospitalization: based on the patient's own desires and the desires of her relatives, the patient was released for home care in the condition of high-level inflammation, progressive kidney failure, aggravated malnutrition, and persisting pains and dyspnoea in the clinical picture.

- During hospitalization, HD was applied 13 times.

- The patient's relatives insisted on hemodialysis throughout the hospitalization period.

- The patient, exhibiting a serious disorder of cognitive functions and developing disorientation, was not able to communicate on her treatment and continued hemodialysis.

- The nephrologist recommended continuing hemodialysis treatment twice a week. 
Four days after release from hospital, the patient was hospitalized again based on the decision of the nephrologist due to terminal condition diagnosis based on progressive kidney failure refractory to treatment. HD was withdrawn due to low blood pressure and cardiac failure. Ten hours after hospitalization, the patient suffered from a quantitative consciousness disorder and died.

Conclusion: Terminal condition of disease

Patient in a terminal condition (kidneys, heart, lungs)

Frailty index for elders - terminal frailty stage

High degree of deterioration in the elderly: high degree of cachexia, chronic immobilization syndrome, decubitus

Catheter sepsis, hypercoagulation condition

Progressive chronic kidney disease CKD st. $5 \mathrm{~K} / \mathrm{DOQI}$, refractory to treatment, anuric stage

Ischemic heart disease, chronic heart failure, function group NYHA IV, LV EF 20\%, thrombosis in the right-sided cardiac atrium.

Chronic obstructive bronchopulmonary disease, serious pulmonary hypertension

Vascular dementia, organic affective delusional disorder (similar to schizophrenia).

\section{Casuistics 2 \\ 79-year-old patient, hospitalized for 14 days in 2018}

\section{Pre-disease period}

The basic diagnosis of the patient was chronic, terminal stage $5 \mathrm{~K} / \mathrm{DOQI}$, kidney disease (CKD), - due to diabetes mellitus. He was included in a chronic hemodialysis program in 2015, three times a week. The other chronic diagnoses included the condition after repeated bloodstream infections with applied dialysis catheter. Diet-controlled type II diabetes mellitus developed after a myocardial infarction in 2005. Permanent pacemaker implantation. Recurring heavy inflammation of the gastrointestinal tract. A high degree of cachexia. Chronic immobilization syndrome.

Clinical frailty index: terminal frailty stage.

\section{Hospitalization}

The patient was hospitalized due to ingestion failure, fever, cough and apathy. Due to pneumonia, the patient was administered antibiotic treatment and complete supportive treatment. The clinical condition of the patient during hospitalization showed low blood pressure, unstable blood circulation, permanent apathy and chronic immobilization.

Hemodialysis was applied as follows:

- $\quad 3^{\text {rd }}$ day of hospitalization: hemodialysis and intravenous catecholamine application (a drug used to increase blood pressure) due to low blood pressure.

- $7^{\text {th }}$ day of hospitalization: due to the overall condition, a nephrologist recommended reducing the frequency of hemodialysis to twice a week.

- $10^{\text {th }}$ day of hospitalization: serious hypotension (blood pressure at $84 / 45 \mathrm{mmHg}$ ); hemodialysis applied only partially, without ultrafiltration; after 70 minutes, the patient himself asked to cease hemodialysis due to pains and lower limb coldness.

- $13^{\text {th }}$ day of hospitalization: Owing to kidney failure (CKD st. $\left.5 \mathrm{~K} / \mathrm{DOQI}\right)$, refractory chronic heart failure and septic condition, the nephrologist diagnosed a 'pre-terminal' stage. Based on consultations with other doctors, the hemodialysis program was withdrawn.

- $14^{\text {th }}$ day of hospitalization: the patient died. 
The patient's relatives were hesitant about withdrawal from hemodialysis during the hospitalization period. They agreed to withdraw from it one day before the patient's death. The patient suffered from mid-severe cognitive function disorder. As a result, he was not able to communicate on his treatment and hemodialysis continuation.

Conclusion: Terminal condition

Patient in a terminal condition.

Frailty index for elders - terminal frailty stage

Terminal deterioration in the elderly - chronic immobilization syndrome, decubitus, severe cachexia, chronic non-tumoral pain

Left-sided pneumonia (bronchopneumonia syndrome)

Hypocoagulation condition

Chronic kidney inflammation (chronic tubulointerstitial nephritis) and diabetic nephropathy, chronic kidney disease (CKD st.5 K/DOQI) refractory to treatment, anuric stage, secondary mid-severe anemia

ICHS 1 - coronary artery disease, condition after anteroseptal MI (2005), TKS

primoimplantation due to the dysfunction of the sinoatrial (SA) node, chronic refractory heart failure with EF 30- \% f.c. NYHA IV, chronic cardiorenal syndrome

Diet-controlled type II diabetes mellitus

Recurring pancolitis

\section{Casuistics 3}

\section{2-year-old patient, hospitalized for 7 days in 2017}

\section{Pre-disease period}

The basic diagnosis of the patient was chronic kidney failure (CKD st. $5 \mathrm{~K} / \mathrm{DOQI}$ ), anuria, failing kidneys due to diabetes mellitus and atherosclerotic renal artery disease; included in a chronic HD program in 2015, three times a week. Other chronic diagnoses include: condition after repeated catheter sepsis $(2015,2017)$; chronic heart failure, function group NYHA III based on ischemic heart disease and mid-severe heart-valve disease; diet-controlled type II diabetes mellitus, stage of organ complications; anemia of mid-severe degree of chronic diseases; condition after small bowel resection due to ileus (2014), short bowel syndrome; condition after rectum amputation due to carcinoma (2001); condition after RAT (radiotherapy) with colostomy.

Clinical frailty index: terminal frailty stage.

\section{Hospitalization}

The patient was hospitalized due to overwatering, hypotension, dyspnoea, aqueous feces into colostomy, approx. $3000 \mathrm{ml} /$ day, multiple hematomas on the patient's body, $3^{\text {rd }}$ degree decubitus in the lumbar region.

From the beginning of the patient's hospitalization, her blood pressure was low, and blood circulation failed, intravenous medication and solution administration became difficult. Due to advanced kidney disease (CKD st. $5 \mathrm{~K} / \mathrm{DOQI}$ ), ischemic heart disease, function group NYHA IV, left-sided hydrothorax, ascites, respiratory failure with hypercapnia, and hypotension (TK $60 / 40 \mathrm{mmHg}$ ) which did not respond to catecholamine support, the patient's condition was evaluated as terminal; we withdrew from invasive therapeutic puncture of the left-sided fluidothorax and from ascites puncture.

- The patient was provided with a peripheral venous access catheter on her neck at the Clinic of Anesthesiology and Intensive Care (CAIM) for administration of liquids and 
medication; furthermore, we administered ATB therapy, catecholamine (dopamine) by means of an injectomat, oxygenotherapy and analgetics.

- $2^{\text {nd }}$ day of hospitalization: the patient underwent nephrological examination. Due to the clinical condition and severe hypotension, the nephrologist decided on "withdrawing from dialysis treatment. If blood pressure does not exceed $110 \mathrm{mmHg}$ we recommend continuing with maximum conservative management of the patient."

- $\quad 4^{\text {th }}$ day of hospitalization: Based on the insistence of the patient's relative the patient on catecholamine support was administered dialysis. During the whole three-hour hemodialysis, the patient was administered catecholamine (dopamine) by means of an injectomat; voluminous ultrafiltration was not possible, the patient was sleepy (somnolent), complained of pain, and suffered from heavy breathing.

- $6^{\text {th }}$ day of hospitalization: HD for two hours; unstable blood circulation; interrupted dialysis; her clinical condition was evaluated by the nephrologist "as preterminal due to the presence of refractory kidney failure (CKD st. $5 \mathrm{~K} / \mathrm{DOQI}$ ), progressive chronic heart failure, function group NYHA IV, acute global respiration insufficiency, cachexia, and hypocoagulation condition" Dialysis treatment was not indicated.

The patient, with catecholamine support, was transferred from the HD workplace back to the ward; progressive delirium, continuous catecholamine support, other treatment reduced, emphasis on suppression of pain; the patient died on the $7^{\text {th }}$ day of hospitalization. The patient's relatives strictly insisted on hemodialysis during the whole period of hospitalization, and personally accompanied the patient to the HD workplace.

\section{Conclusion: Terminal condition}

Patient $\mathrm{n}$. the terminal stage of disease (kidneys, heart)

Frailty index for elders - terminal frailty stage

Terminal decline of the elderly -chronic immobilization syndrome, decubitus, severe cachexia, chronic non-tumoral pain

Diabetic nephropathy and vascular nephrosclerosis, chronic kidney disease (CKD st.5 $\mathrm{K} / \mathrm{DOQI})$, anuric stage, condition after recurrent catheter sepsis $(2015,2017)$

ICHS and mid-severe heart-valve disease, refractory chronic heart failure, function group NYHA IV, left-sided fluidothorax, ascites

Chronic cardiorenal syndrome

Diet-controlled type 2 diabetes mellitus, in the stage of organ complications, anemia of midsevere degree of chronic diseases

Condition after small bowel resection due to ileus (2014), short bowel syndrome

Condition after rectum amputation due to carcinoma (r.2001), condition after RAT with colostomy

\section{Discussion}

Meaningful and, therefore, appropriate treatment is related to a disease, disability or symptom. It is not related to a therapeutic objective. It is evaluated by a physician with the relevant education.

The definition of futile treatment is affected by value judgements and, therefore, it depends on a specific approach. The significance of a discussion on futile treatment stems from the fact that it refers to the limits of medicine beyond which medicine is powerless. This kind of discussion conceives of death as an inherent part of human life. The effort to achieve medical effects may be perceived by a patient as unsuccessful and futile; it may be perceived as treatment that does not result in saving the patient's life, in maintaining his health or quality of life. This kind of treatment does not respond to the patient's interests because it causes unnecessary suffering. From the point of view of medical ethics, the concept of futile treatment 
may be interpreted as a return to paternalism. A more profound analysis of futile treatment can take the form of the quantitative, qualitative and physiological forms of futility.

Quantitative futility expresses the measure of probability of a positive change in the patient's condition as a result of treatment. Treatment with low probability of success, mostly under $10 \%$, is considered futile. A physician relies on his own experiences, shared experiences, and published data. There have been attempts to employ modelling programs for scoring disease development. These programs have limited applicability to futility prognoses.

Qualitative futile treatment fails to achieve its goals, or it is not compatible with them, and does not improve the patient's life quality. Qualitative futile treatment, for example, maintains a permanent condition of unconsciousness, or results in complete dependence of the patient on intensive medical care. Futile treatment thus has adverse and undesired consequences for the patient.

Physiological futility refers to a situation in which the patient's physiological systems resist any available medical intervention that could reverse the patient's condition. Unlike the former two cases, physiological futile treatment can be decided exclusively by a physician as an expert capable of recognizing the capacity of the treatment to fulfil physiological objectives.

The decision to consider any medical treatment as futile means that it is not commenced, extended, or it is stopped. The treatment then pursues a different objective and employs a different procedure. Treatment which increases the patient's discomfort, suffering and pain contradicts both ethical principles of medicine: nonmaleficence and beneficence. From the ethical point of view, medicine does not have to provide futile treatment. The temporary improvement of a physiological function or of its partial parameters without any improvement in the overall course of the disease, and without the possibility of saving the patient's life cannot be considered a favourable effect of the specific medical treatment.

The fundamental objective of medical treatment is to support and protect human health. Its second objective pursues the patient's benefits. This clinical objective implies the treatment of a man as a whole that affects the patient's personal objectives and long-term benefits, life plan, everything that is perceived as a significant part of the quality of life. A physician himself cannot use the quantitative futility method for making a decision on the meaningfulness of a particular degree of probability of the treatment's success or failure. This would contradict another principle of medical ethics - respect for the patient's autonomy. The qualitative futility method does not enable a physician to estimate the meaningful degree of the patient's personal objectives.

Any evaluation of futile treatment should be based on the relation to life, life as the highest value, life as the fundamental human right. Recognition of the natural life finitude is of principled importance. Some other human rights are also significant in this context, mainly the patient's right to self-determination and human dignity. This right also pertains to the patient's opinion, which must be taken into consideration. It primarily bears on informed consent and the instituting of a previously expressed desire, unless the patient is not able to express his informed consent at the time of decision-making. The physician's ethical and legal duty is to inform the patient. The right to self-determination entitles the patient to accept or reject the proposed medical treatment by way of informed consent on the basis of his attitude to the proposed treatment and by evaluating its futility. The physician is obliged to respect the patient's wish as much as possible. By implication, the patient can reject treatment even if the physician believes in its success, or he can require such treatment which, in the physician's view, has minimum chances to be successful.

The casuistics discussed in this paper illustrate the meaningless treatment of chronic diseases in the stage of terminal condition and aggravated syndromology. The permanence of the patient's adverse clinical condition with progression fulfills the criteria of qualitatively futile treatment. The perspective of physiological futility made us conclude on the treatment's 
meaninglessness and futility due to the terminal stage of geriatric frailty. While the instituting of informed consent could not be employed due to the patients' cognitive incompetence, we consider respect for human dignity a category that enables us to stop the patient's suffering (dysthanasia) and to observe the bioethical principles of nonmaleficence and beneficence.

The basic dilemma of hospitalizing a palliative, i.e., chronically dialyzed, patient concerns our ability to distinguish between a potentially reversible critical condition and the terminal condition. The lege artis procedure in patients in a critical condition is intensive care aimed at the maintenance and improvement of the impaired organs and functions; the lege artis procedure in patients in terminal condition is active palliative care (Sláma, 2010).

Two of the presented casuistics report on initiation of the treatment of an acute critical condition - sepsis and bronchopneumonia in chronically dialyzed patients, and subsequent redefinition of the patients' condition in the course of their hospitalization as a terminal condition. One casuistics reports on a terminal condition of the patient from the very beginning of hospitalization. Hemodialysis was administered to all three patients until their death.

The transition from acute treatment to palliative care must be lege artis evaluated and documented. From the point of view of bioethics, it means decision-making in ethical uncertainty. Traditional philosophical and medical ethics does not have any reliable instruments for decision-making in uncertainty. The whole ethical reflection, its structure and methodology are based on the reflection of certainty rather than uncertainty (Kuře, 2015).

The decision-making strategy for ethical uncertainty offers three options according to which doctors proceed in decision-making situations of medical uncertainty (Rhoden, 1986):

1. Waiting for certainty

2. Statistical prognostic strategy

3. Personalized prognostic strategy

There are three basic types of therapy according to the extent of treatment:

a) Standard therapy (complete treatment) - a therapy lege artis which makes use of all currently available means of intensive care medicine, theoretical knowledge and clinical experiences.

b) Withholding therapy -therapy without extending the currently used diagnostic and treatment procedures for a patient.

c) Withdrawing therapy (basic therapy) -therapy which proceeds according to the decisions on the restriction or withdrawal from the current treatment. It proceeds according to a scheme of restricted discomfort in the stage of dying (Kuře, 2012).

In our casuistics, the Hemodialysis Centre specialists evaluated the clinical situation of chronically hemodialyzed patients on the basis of the 'technical' hemodialysis potential rather than by evaluating the overall condition of the patients. From the point of view of palliative care in the terminal condition, the application of hemodialytic treatment until the death of the patient in the above-mentioned casuistics is an inappropriate treatment. These cases illustrate patients in the terminal stage when the communication with their relatives about withdrawal from dialysis can be considered as delayed. The patients themselves were not competent to express their standpoint on the withdrawal from an inappropriate form of treatment.

The relevant procedures in the Slovak Republic are specified in the document "Recommended procedure for the transition from intensive care to palliative treatment of and care for adult patients who are unable of decision-making at the terminal disease stage." This document resulted from a consensus between the Slovak Society for Anesthesiology and Intensive Medicine (SSAIM) and the Palliative medicine section of the Slovak Medical Society. It was approved by the SSAIM on 20 May, 2014. While it is not a legally binding document, it meets the condition of lege artis procedure in withdrawal from dialysis treatment in severely ill patients. In cases when the withdrawal from therapy by decision of a doctor complies with the lege artis procedure, but the patient or their legal representative insists on this type of health care (e.g., hemodialysis), the health-care provider should appeal to a court and continue the 
treatment until the court makes the decision even if the health-care provider considers the treatment to be futile (Firment, 2015). Clinical practice in the Slovak Republic does not experience court appeals in standard clinical procedures for this type of situation (no such case has occurred in the case-law of the Slovak Republic). The existing legal situation makes medical doctors opt for continuation of inappropriate (hemodialysis) treatment because if the patient or his relatives do not agree with the doctor's decision the doctor risks potential legislative sanctions (in the case of an indicated withdrawal from futile dialysis).

In the case of the patients of the first and the third casuistics, the relatives insisted on hemodialysis treatment in spite of the fact that the patient's condition was evaluated as terminal. A way out of this situation may be an evaluation by a commission (for example, by the ethical commission of a hospital). A professional presupposition for such a procedure is lege artis a definition of the terminal condition of the hemodialyzed patient. Communication about the termination of the hemodialysis treatment with the patient and his/her relatives in the stage of chronic hemodialysis appears to be a taboo subject in the Slovak Republic.

The definition of the terminal stage of an oncological patient specifies the following characteristics: a disseminated or a locally advanced oncological disease or its complications; all possibilities of oncological treatment are exhausted in the situation of irreversible failure of one or more organ systems. A definition of the terminal condition requires a comprehensive evaluation of the clinical condition; a doctor must be sure that the disease imminently endangers the life of a terminally ill patient (Sláma, 2013).

It follows from the application of the 'oncological' definition of the terminal condition that the terminal condition could have been identified in all three casuistics of the patients undergoing chronic HD treatment. Hemodialysis failed due to chronic kidney disease in the terminal stage. Moreover, it was accompanied with hemodynamic instability and refractory chronic heart failure. The clinical frailty index confirmed the terminal frailty stage.

In selecting a personalized prognostic strategy in the critical or palliative situation of a hemodialyzed patient, clinical bioethics systematically evaluates all professional and ethical arguments as well as the patient's condition, and makes a decision on the next procedure in the process of communication with the patient and his/her relatives.

In the case of medical monitoring of patients with chronic kidney disease, communication between the doctor and the patient should start in time, months before the intended dialysis, in stage 4 of CKD (Moss, 2001; Brown, Murtagh \& Murphy, 2011). The planning should be implemented with respect to the patient's autonomy and their right for dignity.

Withdrawal from or withholding of dialysis is ethically and clinically acceptable if it is preceded by a joint patient-doctor decision in the process of clinical bioethics. Time-trial dialysis is a possible solution if the patient hesitates whether or not dialysis should be started. It can extend over a specified time period of dialysis (4-6 weeks) (Moss, 2001).

Integration of early palliative care can prolong the life of high-risk patients with progressive CKD. The objective of palliative care consists of improving the comfort of patients near the end of their life. Possible measures include reduced pharmacotherapy, relieved dietary restrictions, modification of the dialysis schedule, changed transportation to a dialysis workplace, changed frequency of dialysis per week, changed vascular access, etc. Continuous communication with a patient and the patient's family is a must.

The frailty syndrome, functional condition, cognitive dysfunction, depression and the risk of fall are aggravated with the progression of CKD, and predict mortality, hospitalization, subsequent care, and femoral shaft fracture. Any prognosis is rather demanding because, in comparison to oncological patients, we miss clear milestones in the trajectory of chronic kidney disease (Couchoud et al., 2016).

Dialysis centres should develop procedures that specify the time and the method of communication of withdrawal from or withholding of dialysis. The length of life after 
withdrawal from dialysis depends on residual kidney function and the patient's overall condition. All the care should concentrate on the comfort and the management of symptoms; those diagnostic and therapeutic steps which do not contribute to the comfort should be withdrawn, including blood tests (Szonowská, 2018).

Any decision on withdrawal from or withholding of dialysis is preconditioned by the process of clinical bioethics. The score itself is merely an auxiliary tool for evaluating the risk and for facilitating communication with the patient on medical treatment. The decision of withdrawal from dialysis should result from an ethical process of communication between a nephrologist and a patient. Clinical recommendations of American nephrologists (Renal Physicians Association: "Shared Decision Making in the Appropriate Initiation of and Withdrawal from Dialysis" (Moss, 2001) includes ten areas pertaining to the initiation or termination of dialysis. Nephrologists who make use of these recommendations more frequently prefer withdrawal from and withholding of dialysis and time-trial dialysis, and more frequently send their patients to hospices (Holley, 2007). The RPA ethical process covers the following areas: the relation which facilitates joint decision-making, identification of high-risk patients, providing information to patients, estimating and advising patients on the prognosis, planning future care, including its formalities, deciding on dialysis withdrawal/withholding, considering the termination of dialysis in patients who do not benefit from it, time-trial dialysis, conflictsituation regulations, effective palliative care, continuous communication (Brown, Murtagh \& Murphy, 2012).

Palliative care for incurable patients in the terminal stage, with life expectancy of several weeks, rarely months, is provided in a specific clinical and ethical context. Medical procedures which do not contribute to the patient's comfort but prolong the patient's life (e.g., antibiotics, parenteral hydration and nutrition, hemodialysis, artificial pulmonary ventilation) in fact mostly prolong the process of dying and worsen the suffering of the patient and his family. Their application/withdrawal must be decided on individually.

If a medical procedure does not guarantee a positive effect on the patient's health or if saving the patient's life implies a high risk of complications, pain, discomfort and suffering which outweigh the actual clinical contribution of the selected procedure the treatment is not in favour and in the patient's best interest, and therefore it can be labeled as futile or inappropriate treatment. Dysthanasia is the condition of severe patient's suffering related to treatment; the chances for recovery are minimal (Sláma, 2010).

Clinical bioethics suggests an integrated ethical program as a comprehensive approach to addressing ethical issues in clinical practice in patients with advanced CKD. The program is based on a four-level method. Level 1 represents medical indications. Level 2 monitors the patient's preferences. Level 3 evaluates the quality of life of the patient, and level 4 evaluates contextual characteristics of the patient (Jonsen, Siegler \& Winslade, 2010).

The suffering at the end of life is total, and is related to the loss of control of the situation and one's own integrity, to the awareness of no future, dependence, loss of dignity, fear of loneliness, of the unknown, of death. These areas pertain to the patient's personality values, and philosophical 'beliefs' (Czech Society for Palliative Medicine, 2013).

A theoretical bioethical model combines methods of general bioethics and bioethical expertise by making use of professional instructions for disease management in the patient's bio-psycho-socio-spiritual and existential dimensions. The theoretical bioethical model developed for palliative care within general bioethics encompasses situation ethics and nursing ethics, ethics of responsibility and phenomenological philosophy. The preferred principles include human dignity, autonomy and solidarity. The process of clinical bioethics should include a personalized prognostic strategy and clinical pragmatism in accordance with the guidelines for supportive/palliative care. The main objective of palliative strategy is the management of an incurable disease in the bio-psycho-socio-spiritual and existential dimension 
of the patient. In the global bioethical objective, the paradigm of solidarity and social harmony can be related to the authentic mode of existence as a constitutive phenomenon of the being-tofinitude (death). The existential movement philosophy refers to the corporality and temporality of existence in this world. Man is corporeal from the nature of his being, the relation to the world is established by the experienced corporality rather than by acts of thought. Three movements of human existence include the movement of anchoring, the movement of selfprolongation, and the movement of self-gaining which results in self-comprehension. An individual can change his relationship to the universe through awareness of his finitude, which makes him authentic. By means of intersubjectivity, he presents himself to others through interpolation, he masters his finitude and overcomes it (Patočka, 1999).

\section{Conclusion}

The instituting of a prior wish is the decisive medical-legal criterion which enables patients to exercise their right to self-determination and to apply the principle of external autonomy. However, it is de facto unattainable in the clinical practice of the Slovak Republic. The Slovak community and health-care should accept active palliative care. This is conditioned by enacting a corresponding legislation and professional procedures for the Slovak Republic, making use of bioethical methods and models. Futile hemodialysis treatment in the terminal condition of a palliative patient is an inappropriate procedure from the ethical point of view, because it prolongs the suffering of patients and their relatives. The palliative strategy is aimed at managing the incurable disease process in the patient's bio-psycho-socio-spiritual continuity. The global bioethical objective for palliative care is based on the paradigm of social harmony and solidarity related to an authentic mode of the patient's existence as a constitutive mode for the phenomenon of his being-to-finitude (death).

\section{References}

BROWN, E., MURTAGH, F. \& MURPHY, E. (2012): Communication with patients and families. In: E. Brown, F. Murtagh \& E. Murphy (eds.): Kidney Disease: From advanced disease to bereavement, 2nd ed. Oxford: Oxford University Press, pp. 199-224.

COUCHOUD, C., HEMMELGARN, B., KOTANKO, P., GERMAIN, M. J., MORANNE, O. \& DAVISON, S. N. (2016): Supportive care: time to change our prognostic tools and their use in CKD. In: Clinical Journal of the American Society of Nephrology, 11, pp. 1892-1901.

Czech Society for Palliative Medicine (2013): Standardy paliativní péče 2013 [Palliative care standards 2013].[online] [Retrieved December 15, 2019] Available at: https://www. paliativnimedicina.cz/paliativni-pece-v-cr-v-roce-2013/

FIRMENT, P. (2015): Terminálna fáza l’udského života a poskytovanie zdravotnej starostlivosti z pohl'adu práva [The terminal phase of human life and the provision of healthcare from the perspective of law]. In: Anestéziológia a intenzívna medicína (SOLEN), 4(2), pp. 7577.

GRACE, B., HURST, K. \& MCDONALD, S. (2012): ANZDATA 35th Annual Report 2012. Australia and New Zealand Dialysis and Transplant Registry.

HEDAYATI, S. S., MINHAJUDDIN, A. T., TOTO, R. D., MORRIS, D. W. \& RUSH, A. J. (2009): Prevalence of major depressive episode in CKD. In: American Journal of Kidney Diseases, 54, pp. 424-432.

HOLLEY, J. L. (2007): Palliative care in end-stage renal disease: Illness trajectories, communication and hospice use. In: Advances in Chronic Kidney Disease, 14(4), pp. 402-408. JONSEN, A. R., SIEGLER, M. \& WINSLADE, W. J. (2010): Clinical ethics. A practical approach to ethical decisions in clinical medicine, 7th ed. New York: McGraw-Hill Medical. KUŘE, J. (2012): Kapitoly z lékařské etiky [Chapters from medical ethics]. Brno: Masarykova univerzita. 
KUŘE, J. (2015): Rozhodování o péči o novorozence na hranicích viability [Deciding on the care of newborns on the borders of viability]. In: Časopis zdravotnického práva a bioetiky, 5(1), pp. 63-85.

MOSS, A. H. (2001): Shared decision-making in dialysis: The new RPA/ASN guideline on appropriate initiation and withdrawal of treatment. In: American Journal of Kidney Diseases, 37, pp. 1081-1091.

MURTAGH, F. E., BURNS, A., MORANNE, O., MORTON, R. L. \& NAICKER, S. (2016): Supportive care: Comprehensive conservative care in end-stage-kidney disease. In: Clinical Journal of the American Society of Nephrology, 11, pp. 1909-1914.

MURTAGH, F. E., MARSH, J. E., DONOHOE, P., EKBAL, N. J., SHEERIN, N. S. \& HARRIS, F. E. (2007): Dialysis or not? A comparative survival study of patients over 75 years with chronic kidney disease stage 5. In: Nephrology Dialysis Transplantation, 22, pp. 19551962.

PATOČKA, J. (1999): Péče o duši II. Sebrané spisy [Care for the Soul, vol. II: Collected Works]. Praha: Oikoymenh.

RHODEN, N. K. (1986): Treating Baby Doe: The ethics of uncertainty. In: The Hastings Center Report, 16(4), pp. 34-42.

RYCHLÍK, I. \& LOPOT, F. (2017): Statistická ročenka dialyzační léčby v ČR za rok 2016 [Statistical Yearbook of Dialysis Treatment in the Czech Republic in 2016]. Česká nefrologická společnost. [online] [Retrieved December 15, 2019] Available at: http://www.nefrol. cz/odbornici/dialyzacni-statistika

SLÁMA, O. (2010): Co je postup lege artis u pacientů v terminálním stavu? Aktuality v onkologii [What is the lege artis procedure in terminal stage patients? Oncology news]. In: Klinická onkologie, 23(3), pp. 182-183.

SLÁMA, O. (2013): Co je postup lege artis u pacientů v terminálním stavu? [What is the lege artis procedure in terminal stage patients?]. In: R. Ptáček, P. Bartůněk \& J. Mach et al. (eds.): Lege artis $v$ medicine [Lege artis in medicine]. Praha: Grada Publishing, pp. 125-130.

SZONOWSKÁ, B. (2018): Paliativní péče v nefrologii [Palliative care in nephrology]. In: Časopis lékař̃u českých, 157(1), pp. 25-29.

U. S. RENAL DATA SYSTEM (2011): Incidence, prevalence, patient characteristics and treatment modalities. In: USRDS 2011 Annual Data Report: Atlas of Chronic Kidney Disease and End-Stage Renal Disease in the United States. Bethesda: National Institutes of Health, National Institute of Diabetes and Digestive and Kidney Diseases.

U. S. RENAL DATA SYSTEM (2014): Incidence, prevalence, patient characteristics and treatment modalities. In: USRDS 2014 Annual Data Report: Atlas of Chronic Kidney Disease and End-Stage Renal Disease in the United States. Bethesda: National Institutes of Health, National Institute of Diabetes and Digestive and Kidney Diseases. 